\title{
ANTECIPAÇÃO, COMPLEXIDADE NARRATIVA E O MELODRAMA PATERNAL EM THIS IS US
}

\author{
Mariana Baltar ${ }^{1 *}$ \\ Carolina Amaral ${ }^{\text {** }}$ \\ ${ }^{1}$ Universidade Federal Fluminense, Niterói, RJ, Brasil
}

Resumo

Este artigo pretende apontar reconfigurações na matriz do melodrama empreendidas especialmente na série This is us (2016 -). Partindo da análise da obra, observamos como as tradições do melodrama maternal são atualizadas em torno de um melodrama paternal, construindo uma imagem de masculinidade que recupera noções de cuidado e sensibilidade, restituindo valores familiares. Apontamos também como essa série de sucesso se apresenta como inovadora através do uso intenso do controle temporal em uma narrativa não linear que, também. nesse ponto, acaba por atualizar outro elemento estético fundamental do melodrama: a antecipação.

Palavras-chave: Melodrama; Controle Temporal; Excesso; Ficção Seriada

\section{ANTECIPATION, COMPLEX TV AND THE PATERNAL MELODRAMA IN THIS IS US}

\begin{abstract}
This article features new shifts in melodramatic cultural matrix analyzing the TV series This is us (2016 - ). By focusing on this show, we argue how traditions of maternal melodrama are reclaim into what can be defined as paternal melodrama. Paternal melodrama creates images of masculinity that capture notions of care and sensitivity in order to restitute family values. We also argue that this successful series innovates in storytelling by intensifying temporal control strategies in a nonlinear narrative, which, ultimately, reconfigures another fundamental melodramatic aesthetic strategy: anticipation.
\end{abstract}

Keywords: Melodrama; Temporal Control; Excess; TV Series

\footnotetext{
* Doutora em Comunicação pela Universidade Federal Fluminense (UFF). Professora da graduação em Cinema e Audiovisual da UFF. Desenvolve pesquisas sobre os estudos de melodrama, políticas de gênero e sexualidade, e a dimensão do afeto e do excesso como estratégias estéticas e matrizes culturais para dar conta do lugar do corpo, das sensações e das emoções no contexto da cultura audiovisual contemporânea. É pesquisadora do CNPq, professora do Programa de Pós-Graduação em Cinema e Audiovisual (PPGCine-UFF) e coordenadora do grupo de pesquisa NEX - Núcleo de Estudos do Excesso nas Narrativas Audiovisuais. Além de diversos artigos, publicou em 2019 o livro Realidade Lacrimosa, pela EdUFF. Seu e-mail é: marianabaltar@id.uff.br. ORCID: https://orcid.org/0000-0002-2314-2015.

**Doutora em Comunicação pela Universidade Federal Fluminense (UFF). Realiza pesquisas no campo da narrativa, cinema de gênero e estudos de roteiro. Atualmente, é coordenadora do ST Estudos de Roteiro da Socine (2020-2022) e desenvolve junto ao Programa de Pós-Graduação em Cinema e Audiovisual (PPGCINE-UFF) a pesquisa de pós-doutorado "Conforto Narrativo: melodrama, crise e catarses de ficções seriadas televisivas" (Faperj, PDR10 2019). Seu e-mail é: carolinaoa@id.uff.br. ORCID: https://orcid.org/0000-0003-2986-7348.
} 


\section{Introdução}

"Eu gosto de imaginar que talvez um dia você seja um velho como eu e, conversando com um jovem você explique como pegou 'O' limão mais amargo que a vida ofereceu e transformou em algo parecido com uma limonada”. Essa frase é dita logo no piloto da série estadunidense This is us. No episódio, o Dr. K. dá a notícia para Jack Pearson da morte no parto de um dos trigêmeos que a sua esposa Rebecca estava esperando. Em seguida, explica como ele próprio perdeu seu primeiro filho no parto, o que o levou a escolher essa profissão. A frase não só conforta Jack, como fornece o mote para um dos eventos motivadores do enredo central, apresentando também, para nós espectadores, a atmosfera que guiará a série. This is us traz a família Pearson e o desdobrar de eventos que ocorrem ao longo dos anos, de maneira não linear, contando simultaneamente a história dos pais, dos filhos e dos netos.

This is us trouxe o melodrama familiar da TV aberta de volta aos círculos de premiação e prestígio. Criada por Dan Fogelman e exibida desde setembro de 2016 pelo canal aberto americano $\mathrm{NBC}^{1}$, a série se distancia bastante das histórias de anti-heróis (The Sopranos, Breaking Bad, Mad Man), ou gêneros fantásticos (Game of Thrones, Walking Dead, American Horror Story) muito populares e que ditavam os rumos nos domínios dramáticos televisivos até então.

Na série, o casal branco Rebecca e Jack decide adotar uma criança negra que nasceu no mesmo dia que seus trigêmeos e fora abandonada. Temas como gravidez, maternidade, paternidade, adoção, raça, alcoolismo, luto e disputas em família são trabalhados ao longo das temporadas. O tratamento melodramático empreendido pela série, ao mesmo tempo em que articula uma construção moral do valor de família, apresenta um discurso geral de otimismo, reiterando a mensagem contida no dito popular mencionando em diversos momentos que preconiza a importância de transformar "o limão amargo em limonada". Desse modo, a série cumpre o "destino" pedagógico de todo melodrama: a reiteração dos valores da família burguesa, ainda que com roupagens contemporâneas de reconfiguração do núcleo familiar dessa mesma família.

This is us não inova apenas na forma não linear de narrar, atuando através de um intenso controle temporal, com idas e vindas no tempo da narrativa. A série também atualiza elementos da matriz cultural melodramática, oferecendo aos seus espectadores novas configurações para velhas e eficazes fórmulas de engajamento. Em tempos de insegurança, crises e incertezas, retomar tanto o valor tradicional da família, quanto o gênero tradicional do melodrama parece ser um alento e um aceno para a audiência massiva.

Neste artigo, apresentamos a hipótese de que tais atualizações do melodrama acontecem em dois níveis: a) fazendo uso intenso da antecipação: vinculando esta figura estética considerada típica do melodrama com elementos de controle temporal, e se aproximando do que Jason Mittell $(2012,2015)$ chama de "complexidade narrativa”; b) atualizando a matriz de um melodrama maternal para um melodrama paternal, com isso construindo uma outra imagem de masculinidade. 


\section{Melodrama: simbolização exacerbada, obviedade e antecipação}

Mais que um gênero sobre temas chorosos, o melodrama é uma imaginação: um formato que se articula a partir do excesso para nos capturar em engajamentos afetivos que mobilizam identificações, exercendo, assim, um papel acima de tudo "moralizante". Por isso, Peter Brooks (1995) entende o melodrama como uma grande e importante pedagogia moralizadora da modernidade ocidental, argumentando que tal imaginação e pedagogia foram fundamentais no conturbado contexto das revoluções burguesas. O gênero ensina preceitos morais para serem exercidos/apreendidos cotidianamente pelo sujeito comum e aposta que a melhor forma de ensinar valores como virtude e vilania é fazer tais (e outros) valores se presentificarem em personagens, objetos, imagens e corpos. A eficácia histórica do melodrama como imaginação, que se consolida em repertórios temáticos e estéticos, está sustentada naquilo que Mariana Baltar $(2012,2019)$ chama de uma pedagogia das sensações.

Linda Williams (2001) se refere a um "modo melodramático" já que, segundo essa autora, o melodrama não se encontra apenas em obras de ficção, mas "na representação da guerra pela mídia, em competições esportivas e tribunais" (WILLIAMS, 2001, p. 12, nossa tradução ${ }^{2}$ ) com uma abrangência elástica de percorrer séculos, mídias e formatos. Christine Gledhill (1987, p. 01, nossa tradução ${ }^{3}$ ) lembra que o melodrama é "uma forma internacional e complexa com duzentos anos de história" normalmente ligado à burguesia, ao crescimento das cidades e à expansão do capitalismo. Também é chamado de "o drama da moral", no qual cada gesto encena o mecanismo de uma moral carregada do conflito entre a salvação e a perdição, num mundo pós-sagrado de dualidades e extremismo. No cinema e audiovisual, o reconhecimento do melodrama foi sendo confinado aos dramas familiares e domésticos, supostamente orientados para públicos femininos e construindo imagens de feminilidade.

Estudos consagrados dessa matriz e gênero no cinema desde os anos $1970^{4}$ destacam três elementos estéticos característicos do melodrama: simbolização exacerbada, obviedade e antecipação. Ao longo da série, faz-se uso intenso dos mecanismos de simbolização exacerbada e, até certo ponto, embora com bem menos presença, da obviedade. Contudo, em This is us, será a antecipação que terá um uso inovador que coloca a série no hall das narrativas complexas contemporâneas ${ }^{5}$.

A simbolização exacerbada (ELSAESSER, 2003) é um procedimento de presentificação básico do melodrama, em que os valores morais são sumarizados no interior das narrativas através de metáforas de intenso apelo visual. Esse "presentificar" implica um fazer encarnar em símbolos exacerbadamente reiterados pelo corpo fílmico - por exemplo, no uso de elementos como o desenho dos planos (posições em cena e gestos), luz, direção de arte, figurino e desenho sonoro - os dilemas morais e sentimentais do enredo. Trata-se de uma economia definida por Brooks (1995) como superdramatização que sedimenta o convite ao engajamento passional e afetivo do gênero. 
O melodrama está vinculado ao estabelecimento de uma relação emocional (sentimental e sensorial) ativada pelo excesso através da exacerbação da retórica, da gestualidade, do ilusionismo, da música, de uma mise-en-scène articulados em uma prerrogativa de reiterações e saturações.

O diferencial do melodramático está na articulação dessa pedagogia moralizante, que se faz eficaz pelo caráter de engajamento sentimental - pela dinâmica de mobilização entre público e narrativa. É nesse sentido que noções como as de arrebatamento, sedução, estímulos e reações sentimentais e sensoriais tornam-se importantes elementos da pedagogia melodramática (BALTAR, 2019, p. 103).

Como consequência desses elementos, é muito comum que histórias melodramáticas se utilizem de polaridades morais para compor personagens que personificam muito claramente o bem ou o mal e os conflitos da narrativa. Também, é comum a utilização de signos de fácil apreensão, já cristalizados no imaginário cultural, para facilitar a apreensão dos processos de simbolização operados na narrativa. Com isso, no melodrama tradicional, simbolização e obviedade andam juntas. This is us, no entanto, evita polaridades, recusando, de certo modo, a obviedade característica dos melodramas tradicionais. Ao longo das quatro temporadas lançadas até a data da escrita do presente artigo, há uma disputa frequente entre os irmãos Randall e Kevin como se representassem imagens de masculinidades geradas a partir do legado da linhagem inaugurada por Jack. Contudo, não há uma polaridade entre os dois: cada personagem é vilão e herói da sua própria história e os conflitos familiares são retratados sem maniqueísmo ${ }^{6}$.

Por outro lado, a série não deixa de se inserir na matriz do melodrama recuperando a simbolização exacerbada como mecanismo e, especialmente, atualizando o elemento da antecipação. O feriado de Thanksgiving, a final do Super Bowl, os jogos de golfe, são alguns dos elos narrativos tratados como simbolizações exacerbadas que reiteram moralmente a ideia de família como legado.

As reiterações acontecem no ordenamento da trama que, ao ir e voltar no tempo, seleciona ações que repetem ideias e se relacionam narrativamente. Há a construção contínua de um elo de símbolos a partir de certos motivos do enredo. Tal procedimento já pode ser percebido desde o episódio piloto. O episódio alterna entre o dia do nascimento das crianças, coincidentemente o aniversário de 36 anos do pai (Jack), e o dia em que eles próprios completam 36 anos: Randall, que foi adotado, encontra seu pai biológico; Kevin tem uma crise no set do sitcom em que trabalha como protagonista; e Kate conhece Toby ${ }^{7}$. Os três irmãos, cada qual a sua forma, recomeçam a vida a partir desses incidentes, da mesma forma como os seus pais quando se tornaram pais de três bebês no mesmo dia.

Mas é no uso peculiar da antecipação que This is us a um só tempo reinstaura as supostamente desgastadas tradições do melodrama e se instala como série inovadora. Segundo Steve Neale (1986) antecipação é a principal estratégia narrativa responsável pela comoção e pelas lágrimas. Através de mecanismos de antecipação, informações são passadas ao espectador e não ao personagem, com- 
partilhando um saber ao público que os personagens ainda não têm, assim, produzindo pequenas deixas que nos fazem ficar à espera do que está para acontecer, em estado de suspensão que, quando finalmente realizado, torna-se catártico. O flashback é para Neale (1986) a definição perfeita da antecipação dos melodramas, tendo em Carta de uma desconhecida (1948), dirigido por Max Ophuls, seu caso exemplar. O filme se inicia com um já velho Stefan pondo-se a ler uma mensagem que lhe fora enviada. A carta nos é lida pela voz off de sua remetente, Lisa. "If only you could recognize what was always yours, could have found what was never lost. If only..." [Se ao menos você tivesse reconhecido o que foi sempre seu, poderia ter encontrado o que nunca foi perdido. Se ao menos...]: são as últimas palavras da carta escrita durante a enfermidade da personagem. Uma carta inacabada. Sabemos disso, desde o começo do filme, uma vez que ele é narrado em flashback. Então, é com um certo nó no peito que acompanhamos os encontros e desencontros do casal Lisa e Stefan.

Na verdade, acompanhamos Stefan encontrar-se com Lisa em diversos momentos ao longo da vida e em todos eles apaixonar-se por ela sem saber que, em todas as ocasiões, tratava-se de uma mesma mulher. Nós sabemos, Stefan não. Nós sempre sabemos, ele nunca, até a carta final, que chega tardiamente, quando a amada já está morta. Esse nosso saber reforça o engajamento, pois, desde o começo sabemos que será tarde demais para o casal. Esse conhecimento prévio faz recair sobre as belas cenas de exaltação desse par amoroso uma sombra de tristeza. Em This is us, a antecipação não se limita ao flashback, mas a todo um complexo sistema de controle temporal que faz a narrativa ir e voltar, uma estratégia de storytelling, que escolhe adiantar elementos da história produzindo expectativas que são muito operacionais e que, associadas ao caráter singular da experiência da serialização, garantem o engajamento e a fidelização da audiência.

\section{O "tarde demais" e o controle temporal narrativo}

A antecipação não é a única forma de controle temporal para criar uma tensão narrativa. Meir Sternberg (1978) menciona outras três estratégias principais: suspense, surpresa e curiosidade. O suspense projeta informações e ações para o futuro, ou seja, retarda o tempo, contribuindo assim com o clímax da história - a imagem de alguém que se segura pelos dedos no penhasco, e a expressão "cliffhanger" que significa gancho narrativo e interrompe ações entre blocos ou entre episódios, são maneiras de criar suspense. Para Yves Lavandier (2003) o suspense está baseado em dar o máximo de informação ao espectador para que ele entenda e participe da história. No suspense, há uma dilatação temporal da ação que permite uma maior gratificação na sua conclusão. Um exemplo já clássico é dado por Hitchcock em suas entrevistas a Truffaut (2004) e se refere à existência de uma bomba embaixo da mesa: se vemos que a bomba está lá e acompanhamos que o estouro está prestes a acontecer, temos um suspense. Ao passo que, se a bomba explode sem nosso conhecimento, temos uma surpresa. A surpresa aparece de repente e é um susto para personagens e espectadores ${ }^{9}$. 
Diferente do suspense que possui uma gratificação no tempo, a gratificação da surpresa é curta, ao que Lavandier (2003) chama de "golpe de efeito". Por sua vez, a curiosidade (STERNBERG, 1978), que Lavandier (2003) chama de mistério, nega informações deixando uma grande interrogação para quem acompanha a história. Como coloca Lavandier (2003), o mistério cria uma hierarquia em relação ao espectador que sabe menos que os personagens e se cria uma tensão com a história: o saber é tranquilizador e por isso, preferimos saber um segredo que estar fora dele (LAVANDIER, 2003). A antecipação, já apresentada anteriormente, antecipa informações cruciais que serão reveladas mais adiante na história. Qualquer que seja o mecanismo de controle de informação fica bem claro sua interlocução, sua vontade de provocar efeitos na leitura, estabelecendo jogos de expectativa entre narrativa e espectador.

Por se tratarem de estratégias de distribuição de informação, os gêneros narrativos costumam utilizar várias, mas eleger uma ou outra como mais importante. O suspense, por exemplo, é usado em diversos formatos narrativos, e Sternberg (1978) analisa o suspense no romance Oliver Twist, mas são as histórias policiais, ou o gênero que chamamos em português de suspense (thriller) que o transforma no elemento central da intriga.

Algo semelhante acontece com o melodrama: existe suspense, como em ganchos narrativos, surpresa, com a revelação abrupta de algum elemento na trama, e mistério, com o desaparecimento de personagens que não se sabe o paradeiro, mas é a antecipação o elemento-chave para a distribuição de informações na história e o principal vetor do controle temporal. A partir da antecipação, o leitor/espectador tem informações e sabe mais que o protagonista, o que causa comoção e engajamento, muitas vezes, lágrimas. Williams (2003) usa a ideia de "temporalidade" para entender o funcionamento narrativo do melodrama ${ }^{10}$. Para a autora, gêneros narrativos inspiram temporalidades, ou seja, efeitos temporais no engajamento com o espectador. No melodrama, a tristeza é intensificada pela temporalidade do "tarde demais"; tudo está perdido e não há o que fazer.

Um exemplo do uso de diferentes estratégias de controle temporal em This is us diz respeito à morte do patriarca Jack Pearson. Sabemos, desde o início da primeira temporada, que Jack morre quando os filhos são adolescentes. Porém, não sabemos como nem por quê. Ao longo da segunda temporada, vamos descobrindo informações sobre essa morte. Sabe-se que aconteceu por causa de um incêndio na casa da família, mas durante os primeiros treze episódios da segunda temporada, informações cruciais são sistematicamente negadas, reforçando o tom de mistério e criando intensa curiosidade sobre o evento. No episódio em que se revela o mistério sobre a morte, os cortes dos blocos coincidem exatamente com momentos de ação inconclusa na trama, criando pequenos cliffhanger folhetinescos no interior do mesmo episódio, elemento típico de suspense.

Quando vemos que Jack, na verdade, não morreu no incêndio, mas do coração, como consequência do incêndio, a temporalidade que impera é a do "tarde demais". Jack voltou na casa em chamas para salvar o cachorro e o álbum de fotos da família e, por isso, inalou mais fumaça que os outros. Jack parece bem 
até segundos antes de passar mal sozinho no quarto de hospital e morrer. A temporalidade do "tarde demais" é mencionada verbalmente por Randall na quarta temporada ao dizer que se culpa por não ter impedido o pai de entrar mais uma vez na casa em chamas. Para reforçar tal temporalidade, a série dedica um episódio inteiro ${ }^{11}$ à vida imaginada por Randall se agisse diferente e seu pai não tivesse morrido. A cena crucial e imaginária em que Randall impede seu pai de entrar na casa uma última vez é seguida de um abraço entre pais e filhos em frente a casa em chamas, em câmera lenta e trilha sonora de tensão. Por se tratar de um final feliz que não aconteceu, a temporalidade do "tarde demais" é o efeito reforçado uma vez mais em relação ao principal drama da série.

\section{Melodrama, temporalidade e complexidade narrativa}

Paul Ricoeur (1995) afirma que a narrativa organiza a nossa experiência temporal informe e, no limite, muda, numa seleção, com assuntos, climas e ritmos. Da mesma forma, Peter Brooks (1984) acredita que o prazer com a narrativa vem de dois pontos: a existência de um fim que dá sentido à história narrada e a ordenação da história enquanto uma intriga narrativa, algo que inexiste na nossa experiência diária. Tais afirmativas sobre a relação entre o tempo e a intriga, a organização e a administração de informações, implicam que, em alguma medida, qualquer narrativa é também uma história sobre o tempo. O passar do tempo, o discorrer do tempo que circula entre o tempo sempre presente da leitura e os diversos tempos possíveis de se narrar. Quando Williams (2001) atribui a uma "temporalidade" como efeito principal do melodrama, ela está sobressaltando o quanto o melodrama é um gênero sobre a perda e, também, sobre o tempo: "O tempo é o objeto principal da perda: choramos pela irreversibilidade do tempo. Choramos em funerais, por exemplo, porque é quando sabemos que finalmente e para sempre, é 'tarde demais"' (WILLIAMS, 2001, p. 31, nossa tradução ${ }^{12}$ ). Essa autora ainda completa que podemos chorar até em melodramas com finais felizes porque a possibilidade do "tarde demais" segue a nos assombrar mesmo "quando, esperança atrás de esperança, o desejo é satisfeito e o tempo vencido" (WILLIAMS, 2001, p. 31, nossa tradução ${ }^{13}$ ).

This is us apresenta uma estrutura temporal que salta de uma época à outra, caracterizando continuamente os personagens e reiterando elementos narrativos que ocorrem em diversas gerações, além de aproximar num mesmo episódio à motivação e às consequências no desenvolvimento das tramas. A série já foi analisada pelo uso contínuo do flashback (ZUBERBUEHLER, 2018), mas a ideia de um flashback, ou mesmo um flashforward remete a uma estrutura temporal linear que a série nunca apresentou.

A principal característica em termos de estrutura da série é a apresentação dos eventos como num quebra-cabeça temporal. Estrutura e objeto não estão tão afastados na medida em que é também o passar do tempo entre fases da vida e gerações, - e, portanto, uma ideia de linhagem familiar - o tema principal da história. Ainda que façamos a ressalva de que todas as narrativas seriadas ocor- 
rem no tempo e essa organização de capítulos, episódios e hiatos trazem a espera para o interior da história, This is us vai além ao transformá-lo num tema central. A série entrelaça o passar do tempo como legado e memória, com temas que se repetem em diversos personagens da mesma família.

Por exemplo, no episódio 5 da primeira temporada, é antecipada uma cena em que Randall arruma o quarto de William, seu pai biológico, após sua morte. Ainda não vimos a sua morte, mas sabemos desde a primeira aparição de William (no piloto) que ele tem um câncer terminal. A cena é coberta pela conjunção de uma música instrumental e da voz off de Kevin explicando a morte e as linhas de continuidade familiar para as sobrinhas. "talvez não haja realmente morte, e as pessoas que morrem continuem com a gente". O que ao cabo é a sumarização, ao mesmo tempo, do projeto narrativo da história, e de sua ideia de paternidade e família. Por um lado, ao ressaltar o legado familiar, This is us se aproxima de um tema típico do melodrama. Por outro, ao apresentar a morte como algo não definitivo, a temporalidade do "tarde demais" se torna um efeito momentâneo, a fim de provocar comoção pontual. O resultado é uma adesão transformadora ao melodrama familiar enquanto gênero.

A aceitação da morte, do infortúnio e a valorização da capacidade de seguir adiante formam a atmosfera da série que aproxima o melodrama de um otimismo normalmente associado à comédia e ao cômico. Suzane Langer (1981) entende a comédia como um ritmo; um ritmo que assim como o ritmo da vida, está sempre se movendo, equilibrando fortuna e infortúnio, não do ponto de vista da morte, como acontece na tragédia, mas do ponto de vista do continuar incessante, da capacidade de durar. Segundo essa autora, a ação cômica conquista o mundo com uma "bem-humorada, ou irônica ou filosófica aceitação do próprio infortúnio" (LANGER, 1981, p. 82, nossa tradução ${ }^{14}$ ) porque não existem triunfos nem perdas permanentes a não ser na tragédia.

Apesar de apresentar momentos bem-humorados, This is us não é uma comédia, mas carrega algo da atmosfera cômica que torna mais leve a história, por mais pesados que sejam os temas discutidos. Ao trazer um melodrama familiar aberto a uma atmosfera cômica, This is us apresenta uma característica central do que Mittell $(2012,2015)$ chamou de complexidade narrativa: a mescla intencional de gêneros.

A complexidade narrativa é um conceito usado por Mittell para analisar a produção ficcional dos últimos vinte anos na TV americana e o forte investimento em estratégias narrativas para ficção seriada, de modo a engajar o público com arcos narrativos em diferentes amplitudes. Narrativas complexas trazem a ideia de que "a série é uma narrativa cumulativa que se constrói no tempo, ao invés de restabelecer um equilíbrio inicial ao final de cada episódio" (MITTELL, 2015, p. 18, nossa tradução ${ }^{15}$ ). Como lembra Marcel Vieira (2014, p. 3-4), um elemento central é "o desenvolvimento do percurso dos personagens (protagonistas ou não), desenhados particularmente como identidades instáveis cujo ethos em transformação impulsiona e climatiza o desenvolvimento dramático da história”. 
A complexidade narrativa está relacionada, sobretudo, às estratégias de storytelling, mas também conjuga elementos de produção, inovações tecnológicas e práticas espectatoriais. A ordenação da trama em múltiplos tempos em This is us é uma estratégia de complexidade narrativa, e funciona como o que Mittell chamou de anacronia, que junto com o efeito rashomon desestabiliza a premissa da narrativa unívoca da tradição ilusionista-realista. O efeito rashomon mostra um mesmo evento sendo narrado por diversas perspectivas e é também uma técnica usada na série. Os episódios Number One, Number Two e Number Three (segunda temporada) e A Hell of a week 1, 2 e 3 (quarta temporada) trazem um mesmo evento, tanto no passado quanto no "presente" em três episódios diferentes: cada qual narrado por um dos filhos e trazendo seus dramas íntimos que, num certo momento, colidem. Há o que Mittell $(2012,2015)$ chama de uma "estética operacional" ou um "efeito especial narrativo" quando a história se curva e flexiona seus próprios músculos e impressiona o espectador não apenas pelo que é narrado, mas pela forma como se narra, numa mistura de maquinário e emoção, surpresa e engajamento.

Mittell $(2012,2015)$ também ressalta que a maior parte das narrativas complexas apresentadas no horário nobre da TV americana são "melodramas seriais" que compartilham um vocabulário cultural comum da ação e do sofrimento. This is us é considerado um melodrama familiar, um gênero que estrutura a imaginação melodramática em convenções narrativas e dramáticas. O gênero é voltado para as relações familiares, seus dilemas morais e emocionais, "como se os personagens fossem, por assim dizer, suas únicas referências" (ELSAESSER, 2003, p. 381, nossa tradução ${ }^{16}$ ). Historicamente centralizado na figura materna, o melodrama familiar, também chamado de "melodrama maternal", dialoga com uma ideia de maternidade envolta em autossacrifício e sofrimento: a jornada da mãe que deve abrir mão de tudo para o sucesso dos filhos e, muitas vezes, resignar-se ao seu próprio esquecimento. This is us atualiza essa matriz cultural ao centralizar suas tramas na figura paterna, apostando no que vamos chamar de um "melodrama paternal".

\section{Viril e sensível: o melodrama paternal em This is us}

Nos estudos do melodrama no cinema e audiovisual, as narrativas que se centram na construção moral da família são usualmente denominadas melodrama doméstico ou familiar. São narrativas que oscilam entre a exaltação dos valores da honra e da ordem heteronormativa (usualmente centrando no par amoroso), e o movimento autorreflexivo fazendo com que os próprios valores da família heterossexual burguesa sejam as constrições da felicidade dos personagens, como nos filmes de Douglas Sirk e nos melodramas de Vincente Minnelli ${ }^{17}$.

Mas dentro desse grande escopo, há ainda um topos recorrente em torno da figura materna, sobretudo nos anos 1940, centrando a construção da pedagogia moralizante própria do melodrama nas relações mãe e filho, mãe e filha. Esses melodramas maternais - conforme foi definido em textos clássicos sobre o assunto como os de Christian Viviani (1987), Linda Williams (1987) e E. Ann 
Kaplan (1987) - não acontecem apenas no cinema hollywoodiano e encontramos importantes exemplos no cinema italiano e, em especial, no mexicano.

Nesses filmes, percebe-se que a mãe figura a partir de um jogo de tensões morais entre as dicotomias (casa $v s$ rua, mãe $v s$ mulher sexualizada e sedutora), de uma maneira que consolida o valor da maternidade e, correlatamente, da feminilidade, como sacrifício, abnegação e cuidado, mesmo quando tal sacrifício implica o abandono da filha ou do filho. Uma espécie de autossacrifício em prol do amor e da devoção da mãe em filmes como Stella Dallas (1937), dirigido por King Vidor ou Las Abandonadas (1945), dirigido por Emilio Fernandez.

O "ciclo" do melodrama maternal não se restringe ao cinema da década de 1940, remetendo-se ao teatro melodramático e à literatura popular massiva de fins do século XIX, bem como ao discurso da construção moderna da ideia de maternidade que, conforme argumenta Kaplan (1987), encontra na Émile, de Rousseau, de 1762, um texto fundamental. Nesse sentido, a partir da expressão da figura da mãe se articulam os mais densos medos e fantasias em torno dos femininos sob o patriarcado (KAPLAN, 1987).

O melodrama maternal, em sua veia americana, é uma apologia à renúncia total, ao sacrifício e autoabnegação total. Com exagero melodramático, claro, mas ainda com suficiente adesão ao modo transparente de narrar, em um período quando os Estados Unidos realmente precisavam mobilizar boa vontade e dedicação sem a promessa de recompensa imediata (VIVIANI, 1987, p. 96, nossa traduçãa ${ }^{18}$ ).

Viviani (1987) lembra que se normalmente o cinema estadunidense retrata histórias de sucesso, o melodrama materno, reiteradas vezes, tende ao contrário, mostrando histórias de anonimato e fracasso, por um lado expressando os dramas pessoais intensos inerentes ao gênero, mas, por outro, cristalizando valores de sacrifício individual em prol da criação do futuro. Para esse autor, o melodrama maternal está amplamente ligado a contextos de guerra e de incertezas.

O que queremos levantar neste artigo, ainda que de modo tangencial, é que em tempos de crise e incerteza, como estes da contemporaneidade, o melodrama retorna com força oferecendo certo conforto catártico e formas de expressar, por suas dinâmicas intrínsecas de pedagogia das sensações, locus de supostas e acalentadoras certezas e verdades em descargas emocionais e afetivas.

O que sucessos como This is us na TV estadunidense nos inspiram a refletir é que a contemporaneidade parece ver uma tendência de atualização do melodrama, de retrabalho e reapropriação de sua matriz cultural (repertórios temáticos das suas tradições) e, especialmente, de suas estratégias estéticas expressivas pautadas na eficácia do excesso como cristalizador de potentes convites ao engajamento sentimental e afetivo.

Mais especificamente, o topos próximo do melodrama maternal volta em This is us para a reiteração do valor de família e de sua exaltação como porto seguro para os sujeitos frente a crises e a inseguranças. Contudo, em um contexto de apropriação midiática da agenda do feminismo branco, não parece ser 
desejável para a cultura e para a sociedade do espetáculo retomar a figura da mãe como símbolo expressivo dos valores de abnegação, cuidado e família. Nosso argumento é que a figura paterna é perfeita para mecanismos de atualização da matriz melodramática. É nesse sentido que propomos a análise de This is us como melodrama paternal.

Como comentamos, no melodrama maternal há uma construção de feminilidade associada à maternidade, principalmente na figura sacrificial da mãe. Nesse sentido, sacrifício, abnegação e cuidado são tratados através das formas expressivas do excesso melodramático, como valores naturalmente domésticos e femininos. A inversão que se coloca no que estamos definindo como melodrama paternal, a partir de This is us, é uma construção, nascida da apropriação das mesmas lógicas do melodrama maternal, de uma masculinidade associada à sensibilidade e ao cuidado. A série segue reiterando os mesmos valores masculinos de virilidade, violência e proteção, mas revestidos das noções familiares e domésticas do cuidado, certa dose de abnegação, e o valor humanístico da sensibilidade.

Em suas pesquisas seminais sobre masculinidade e o que definiu como casados-homens, Daniel Welzer-Lang (2001, p. 463) ressalta que para "os homens, como para as mulheres, a educação se faz por mimetismo. Ora, o mimetismo dos homens é um mimetismo de violências". Nesse sentido, os espaços de homossociabilidade conduzem padrões de comportamento do masculino que, segundo o autor, orbitam em torno de signos de violência e virilidade. As pesquisas de Welzer-Lang datam majoritariamente de fins dos anos 1990 e início dos anos 2000 e levam em consideração um contexto euro-norte americano. Contudo, seus apontamentos podem ser balizares para demarcar como imagens e modelos de comportamento construídas no âmbito dos imaginários culturais e no âmbito dos espaços institucionalizados de sociabilidade entre homens forjam a construção dos valores hegemônicos de masculinidade. É claro que tais valores sofreram mudanças progressivas - inclusive no que diz respeito aos paradigmas de virilidade em sua associação com o distanciamento emocional-afetivo - e tais mudanças não deixam de ser fruto também das próprias pressões simbólicas dos feminismos e das políticas de gênero.

Em História das Lágrimas, Anne Vincent-Buffault (1988) aponta o que pode ser entendido como uma hierarquia cultural de gênero do sensível. $O$ que ao longo do século XVIII era valorizado com demonstrações públicas - aquilo que a autora chama de excessos demonstrativos - vai se transformando, no século XIX, em sinal de maus modos por uma ideologia de valorização da contenção, que relega as lágrimas e a explicitação da sensibilidade à esfera da intimidade e do feminino: "É na segunda metade do século XIX que a lágrima rara torna-se valor ascendente da sensibilidade masculina, enquanto as mulheres, dominadas por uma emotividade excessiva, não são mais celebradas, pelo contrário" (VINCENT-BUFFAULT, 1988, p. 14).

O século XIX vai gradativamente construindo a sensibilidade - ou a capacidade de expressar o ser sensível e emotivo - como um vetor de diferenciação entre feminilidade e masculinidade. Jovens autores e artistas europeus da segunda 
metade do século XIX reivindicavam uma reação contrária ao que consideravam "exibições de sentimentos" e "extravasamentos das almas sofredoras" em nome da virilidade:

O gosto pela observação fria e o desprezo por uma poesia nascida da efusão estão associados no espírito de Flaubert aos valores viris. [...] Seu desprezo pelas poses lacrimejantes do poeta romântico é acompanhado de uma vontade de dizer a verdade que exige uma segurança máscula. [...] A afirmação é clara: é necessário expurgar das Letras as secreções femininas que as tornaram insípidas e fazer prova de uma virilidade que delas destina-se radicalmente (VINCENT-BUFFAULT, 1988, p. 214-215).

As lágrimas e a expressão sensível não foram de todo expurgadas, nem nas Letras nem na cultura cinematográfica ou audiovisual que dominou o campo artístico do século XX, mas certamente a hierarquia valorativa que separa obras para as feminilidades e obras para as masculinidades foi uma recuperação direta desse lugar diferencial da sensibilidade, conforme aponta a historiadora francesa.

O século XXI, pós-pressões das teorias e reivindicações feministas e da política de gêneros, e, sobretudo, pós-cooptação destas pelas dinâmicas da sociedade do espetáculo, problematizou esse tal lugar diferencial da sensibilidade, impulsionando mudanças importantes para os conceitos de masculinidade.

o gênero masculino se modifica, integra outros conteúdos, outros valores. O que não quer dizer, aliás - e de longe -, que não tenha havido recomposição da dominação masculina, e que a colocação em dúvida da masculinidade seja linear ou que seja necessário esquecer a articulação entre relações sociais de sexo e estruturação em classes sociais (WELZER-LANG, 2001, p. 471).

Uma masculinidade viril, porém sensível é o que parece ser delineado na cultura contemporânea. Se os espaços público e privado foram, ao longo dos anos, associados respectivamente ao masculino e ao feminino, assim como ideias simbólicas de "força" e "sentimento", as ideias de "maternidade" e de "paternidade" também acompanharam os parâmetros da divisão sexual. Como coloca Medrado (1998), o repertório cultural mais comum é a divisão parental entre o pai provedor material e a mãe provedora afetiva e sensível.

Day e Lamb (2009) afirmam que a ideia de masculinidade foi erguida a partir de um distanciamento emocional-afetivo e na multiplicidade de parceiros sexuais; no entanto, ao longo das últimas décadas, tanto a paternidade quanto a masculinidade sofreram mudanças históricas que indicam uma chave de interpretação nas relações contemporâneas. O melodrama paternal que estamos propondo ${ }^{19}$ performa uma masculinidade associada à paternidade e à esfera doméstica, em consonância com o que se chamou "nova paternidade", conceito surgido nos anos 1980 que indicava uma presença mais forte da figura masculina no cuidado e na criação dos filhos (MEDRADO, 1998).

A figura paternal não é totalmente alijada do universo do melodrama fílmico e audiovisual, e basta lembrar-nos de filmes como O Campeão (1979), com a per- 
formance comovente de Jon Voight, e Kramer vs Kramer (1979), para puxarmos de lá as raízes do que aqui estamos chamando de melodrama paternal. Vivian Sobchack (1991) analisa como alguns melodramas familiares do fim dos anos 1970 (Kramer vs Kramer, Author, Author! e também comédias dos anos 1980 como Mr. Mom, Três solteirões e um bebê) retratam homens que assumem os cuidados dos filhos, e uma "paternidade em ascensão". O termo "melodrama paternal" é usado por Nicola Rehling (2009) Nicola Rehling para nomear uma tendência na matriz cultural popular do século XXI de retratar a "masculinidade heterossexual branca como paternidade" (REHLING, 2009, p. 11, nossa tradução ${ }^{20}$ ).para nomear uma tendência na matriz cultural popular do século XXI de retratar a masculinidade heterossexual branca como paternidade.

Se no melodrama maternal o autossacrifício e a renúncia - inclusive a constructos de feminilidade e desejo - dão a tônica, no melodrama paternal, normalmente se retrata uma história de sucesso ${ }^{21}$. Pais relutantes que pouco a pouco conseguem assumir suas funções cotidianas e domésticas como verdadeiros heróis. Romantiza-se a figura paterna por desempenhar o seu papel de pai, sem que com isso se macule sua masculinidade vinculada a sucesso, heroísmo e virilidade.

Em This is us, arcos narrativos que se desdobram com maior amplitude e costuram todos os episódios, envolvem, em geral, a construção de figuras paternas. A primeira temporada se dedica fundamentalmente a construir Jack e William como pais. As figuras paternas são mais centrais que as maternas, ainda que, no caso dos dois personagens citados acima, essa composição envolva também a ausência deles, provocada pela morte, mas presença constante pela ideia do legado que é expresso de forma cênica, constantemente, através do controle temporal operado no âmbito da narrativa ao longo da série.

Desde o piloto, a estrutura melodramática de criar elos constantes ligando as trajetórias de vidas se apresenta, principalmente, a partir desses dois personagens. Jack, mesmo morto, segue como figura central na segunda temporada, cujo tema principal é a cena e as circunstâncias de sua morte (vista finalmente no episódio 14) e os impactos de sua ausência na vida de todos. A terceira temporada novamente toma o fio de Jack, mas dessa vez desconstruindo-o, mostrando as contradições de um personagem que até então havia sido apresentado como um ideal a ser seguido e idolatrado. Em paralelo, vai-se delineando através do mecanismo de antecipação, um novo Jack (filho de Kate). Já na quarta temporada, Toby e Kevin surgem também como figuras paternas, além do reposicionamento de Randall, que é pai de três meninas, mas passa a ser vereador na Philadelphia, atendendo individual e paternalmente a toda população que necessite de sua atenção.

Para Rehling, há um valor cultural na paternidade que por um lado responde a anseios feministas de equidade doméstica, mas que também "demonstra como é possível para homens atenderem a demandas feministas de maneira a deixar as mulheres mais marginais do que nunca" (REHLING, 2009, p. 18, nossa tradução ${ }^{22}$ ). Nessas histórias analisadas por Rehling (2009), a paternidade costuma apagar a maternidade, com mulheres que morrem antes do filme começar como em Sintonia de Amor (1993), entram em coma como em Os Descendentes (2011), 
ou, simplesmente, abandonam a história como em Kramer vs Kramer. Ao embaralhar os tempos, This is us consegue combinar o sofrimento maternal - a viúva Rebecca perde o amor da sua vida, cria, sozinha, os filhos adolescentes e como ela própria fala no final da quarta temporada, teve uma vida repleta de "na próxima vez", sem nunca conseguir se colocar como prioridade - com essa paternidade alçada a um novo ideal de masculinidade apresentando um Jack compreensivo, participativo, sensível, sexy e herói. Jack também representa um ideal convencional de masculinidade viril ao se sacrificar no incêndio para salvar a família e sua memória representada pelas fotografias resgatadas por ele. Há, de fato, uma atualização e "renovação" das matrizes do melodrama, mas há também uma reiteração do seu lugar moral da exaltação da família e mais, da figura da paternidade como devoção, sacrifício e continuidade/legado.

Jack é o centro desse melodrama paternal, mas não é a única masculinidade exaltada a partir da paternidade. Já falamos anteriormente de William, Randall e Toby, mas podemos analisar outro personagem principal: Kevin. Ele nos é apresentado como um ator do sitcom The Manny, trocadilho que se refere à caricata premissa do show: um babá homem. No piloto de This is us, Kevin aparece nas filmagens de uma cena na qual seu pai no sitcom metanarrativo aparece para visitá-lo depois de longo período de ausência. Tudo parece transcorrer bem até o Manny trazer à tona sua insatisfação pela ausência do pai, de forma raivosa e emocionada. Kevin fica bastante satisfeito com a sua performance, talvez pela primeira vez. No entanto, o diretor pede para ele repetir a cena, agora de forma burlesca. É quando Kevin abandona o show televisivo e expõe ao público que o assiste ao vivo suas razões.

Na terceira temporada, o desejo de Kevin de ser pai, junto com seu alcoolismo - legado do pai - é o impedimento de seu relacionamento com Zoe. Na quarta temporada, somos apresentados ao filho de Kevin, muito rapidamente, já no primeiro episódio, através do uso melodramático da antecipação. Mais adiante na temporada, descobrimos que a doçura com que Kevin interagia com o bebê no sitcom é o que garantiu que o seriado fictício fosse produzido. Em outro episódio da quarta temporada, novamente através de uma antecipação, somos apresentados a sua noiva, ainda sem a revelação de quem seja, e sua gravidez anunciada no aniversário de 40 anos do personagem. Notamos aqui como os mecanismos de antecipação, suspense e reiteração articulam uma rede com a serialização e são utilizados para constituir a paternidade de Kevin. Ao mesmo tempo, lançam pistas sobre o futuro da trama e fazem constantes referências a Jack Pearson.

Ao final da quarta temporada, sabemos finalmente que Kevin será pai não apenas de uma criança, mas de duas, um casal, como ele e sua irmã gêmea. A ideia de legado se renova e a história familiar parece se repetir incessantemente, consolidando com isso efeitos melodramáticos fundados na experiência própria da serialização. Os cenários e ritos familiares - a cabana no campo, o VHS do sucesso teen dos anos 1980, a pouco ortodoxa celebração do feriado norteamericano do Thanksgiving - são repetidos como simbolizações exacerbadas não apenas do valor de família, mas também como legados de uma sensibilidade paternal. 
Kevin, que passou temporadas buscando o amor de sua vida em diversas figuras, afirma, bem perto do cliffhanger do episódio final da quarta temporada, que o amor de sua vida serão seus filhos. Reforçando ainda mais o nosso argumento de que This is us é fundamentalmente um melodrama paternal, por mais que inclua questões familiares, disputas entre irmãos e amores desfeitos. Essa paternidade, construída melodramaticamente a partir do legado de Jack Pearson, é o valor que se sobressai.

\section{Considerações finais}

This is us renova as estratégias melodramáticas retrabalhando valores de família como porto seguro que deve ser cuidado e exaltado face às inseguranças e incertezas da contemporaneidade. Nesse sentido, o melodrama é novamente um lugar de conforto e descarga passional. A série opera retomando de modo atualizado o uso do controle temporal e o efeito da temporalidade "tarde demais" em conformidade com os cânones atuais da complexidade narrativa. Abandona o maniqueísmo que normalmente marcava o gênero em favor de uma complexa e contínua caracterização dos personagens. A previsibilidade dá lugar a tramas não lineares em quebra-cabeças temporais. A reiteração se aproveita da estrutura narrativa para aproximar personagens, motivações e temas que se repetem como legado.

O melodrama maternal dá lugar ao melodrama paternal, e a masculinidade é ressignificada a partir de um ideal de paternidade que, simultaneamente, atende a demandas de um feminismo midiático e espetacular e posiciona as mulheres como personagens satélites.

Nesse sentido, para além do comentado aqui, o uso da trilha sonora é, mais uma vez, forte vetor de gestão das intensidades emocionais no público. Não nos debruçamos sobre essa estratégia tão comum ao gênero - afinal, o melos do melodrama - mas cabe ressaltar como a série usa largamente as baladas setentistas se referindo, ao mesmo tempo, à época em que Jack e Rebecca eram jovens, ou seja, o início de toda a história, e a um sentimento melancólico e nostálgico, emoção passada que parece impossível de se recuperar, e que, no entanto, consolida-se como ideal e modelo.

A capacidade de o melodrama se renovar atesta o que disse Ismail Xavier sobre o melodrama apresentar estabilidade e matrizes sólidas, num mundo em que tudo parece instável. "Provê a sociedade de uma pedagogia do certo e do errado que não exige uma explicação racional do mundo, confiando na intuição e nos sentimentos 'naturais' do indivíduo na lida com dramas que envolvem, quase sempre, laços de família" (XAVIER, 2003, p. 91).

This is us comprova, mais uma vez, a eficácia pedagógica das estratégias do melodrama, mostrando como este é, acima de tudo, camaleônico ao contrário do que dizem parte de seus críticos, que apenas o veem como emparedado e repetitivo. A série consegue abusar do excesso melodramático, calcado em dinâmicas estéticas de reiteração e saturação, para colocar em cena todos os temas de uma agenda de disputas culturais e sociais. 
Maternidade, paternidade, gênero e raça são temas tangenciados nesse melodrama paternal através de elos narrativos melodramáticos forjados pelas simbolizações reiteradas e saturadas no modo de excesso em uso. Os arcos dos personagens, as músicas e até os espaços cênicos, para além dos temas, são mobilizados, pela antecipação e pelo controle temporal, como forças de engajamento emocional e afetivo melodramáticas.

Uma imagem síntese desse melodrama paternal é o tableau de Jack na piscina comunitária, espaço cênico que aparece, pela primeira vez, no quarto episódio da primeira temporada e que retorna no segundo episódio da quarta. A câmera alta enquadra o pai rodeado de seus filhos, a mãe aparece marginalmente nesta imagem, um corpo cortado com uma presença importante, mas do extra-quadro. A luz, com poucas ou quase nenhuma zonas de escuridão, mas com muitos brilhos, ressalta o volume do corpo da filha, a incorporação do privilégio branco e belo de um dos filhos e o contraste da cor escura do outro filho. No centro, os torneados e másculos braços de um pai que abraça e acolhe. Ao cabo, tal tableau, esse quadro congelado que é o melhor exemplo da força reiterativa e saturativa do excesso melodramático, acena confortável e passionalmente para espectadores contemporâneos.

Notas

1. A NBC é uma das três grandes emissoras da TV aberta nos Estados Unidos e a rede de radiodifusão mais antiga do país. Exibiu series de sucesso como Seinfeld, Friends, ER, Law and Order, The Office, dentre outras. No Brasil, This is us é exibida pelo canal Fox Premium e pela plataforma de streaming Amazon Prime Vídeo.

2. No original: "the media representation of war, athletic competitions, and courtroom trials" (WILLIAMS, 2001, p. 12).

3. No original: "cultural form with a complex, international, two-hundred-year history" (GLEDHILL, 1987, p. 01).

4. Os anos 1970 foram fundamentais para uma revalorização do melodrama como modo, sobretudo, para o campo do cinema a partir da publicação de textos fundadores como o de Thomas Elsaesser (2003) e Peter Brooks (1995), ambos publicados pela primeira vez em 1972.

5. Neste trabalho, narrativas complexas fazem referência ao conceito de Jason Mittell $(2012,2015)$ que será discutido mais adiante.

6. O principal indicador de recusa do maniqueísmo explícito que opera This is us é a ausência de personagens vilões, retirando do escopo da trama a estrutura que marcou os melodramas canônicos que demarcavam, de modo muito óbvio, o mal antagonista aos heróis. Mas há outras formas nas quais a série desestabiliza o maniqueísmo, desenvolvendo, ao longo das temporadas, momentos de ambiguidade para os personagens que são tratados como heróis. No decorrer deste artigo, oferecemos alguns exemplos de desconstruções das figuras de heróis e heroínas da série, mas a título de ilustração, já aqui, podemos antecipar o processo de desconstrução de Jack como herói a partir da sua relação com o irmão Nick; ou os episódios que mostram os conflitos entre Rebecca e seu filho Randall; ou, ainda, o arco narrativo dos conflitos entre os irmãos Randall e Kevin ao final da quarta temporada.

7. Toby conhece Kate em uma reunião de grupo de apoio para obesos. O casal se forma logo na primeira temporada e, ao longo da segunda e terceira temporadas, a trajetória de Toby, primeiro como marido e depois como pai, vai se desenvolvendo. 
8. Optamos em apresentar a frase em inglês para demarcar a importância da pronúncia do texto na língua original, que na entonação específica dada pela atriz, faz com que a frase soe como lamento e sussurro.

9. Lavandier (2003) fala ainda da relação entre suspense, surpresa e ironia dramática. A ironia dramática é uma forma de estruturar o suspense, ao negar a um personagem informações essenciais à sua própria trama, mas dá-las ao espectador. A surpresa funcionaria de maneira oposta, revelando de golpe informações essenciais da trama ao espectador.

10. Williams (2003) demonstra uma clara inspiração psicanalítica ao refletir sobre o papel da mulher representada nos gêneros do corpo como um papel masoquista. Nesta investigação, com o texto da autora, decidimos propositadamente obliterar essa inspiração, pois há no interior da teoria feminista do cinema uma revisão das inspirações e vocabulário psicanalíticos, revisão da qual a própria Williams, bem como Laura Mulvey (ver nesse sentido textos de Mulvey em uma revisão de seu paradigmático artigo "Prazer Visual"), participam. No presente artigo, não usamos o vocabulário masoquismo e seus correlatos, embora possam ser válidos para lidar com algumas passagens e reflexões do melodrama; isto porque, seguindo a revisão da crítica feminista do cinema, a partir do final dos anos 1990, o aparato psicanalítico determina lugares polarizados de espectatorialidade, ofuscando as ambivalências que implicam tais experiências.

11. pisódio 17 da quarta temporada, intitulado "After the fire".

12. No original: "Time is the ultimate object of loss; we cry at the reversibility of time. We cry in funerals, for example, because it is then that in practice we know finally and forever, that it is 'too late"' (WILLIAMS, 2001, p. 31).

13. No original: "When, hope against hope desire is fulfilled, and time is defeated" (WILLIAMS, 2001, p. 31).

14. No original: "humorous, or ironical, or philosophical acceptance of mischance" (LANGER, 1981, p. 82).

15. No original: "a series is a cumulative narrative that builds over time, rather than resetting back to a steady-state equilibrium at the end of every episode" (MITTELL, 2015, p. 18).

16. No original: “The characters are, so to speak, each others' sole referente" (ELSAESSER, 2003, p. 381).

17. Esse é um tema recorrente nos melodramas domésticos de Sirk e Minnelli, mas a título de exemplo, podemos citar obras como Tudo o que o céu permite (Douglas Sirk, 1955) ou Paixões sem freios (Vincente Minnelli, 1955).

18. No original: “The maternal melo in its American vein is an apologia for total renunciation, total sacrifice, total self-abnegation. Melodramatic exaggeration, of course, but still transparent enough in a period when America really needed to mobilize good will and dedication without promise of immediate recompense" (VIVIANI, 1987, p. 96).

19. Linda Williams em seu artigo "Film Bodies" faz uma rápida menção que pode nos ajudar a delinear o melodrama paternal; ela utiliza o termo "male weepies" associando de modo generalizado filmes que se centram em laços afetivos entre homens e demonstrações de paternidade. Certamente essa rápida menção, bem como outras indicadas em nossa investigação (como a feita por Nicola Rehling, em 2009), indicam caminhos para conceituar o melodrama paternal. Nossa tarefa aqui neste artigo é delinear de um modo mais detalhado tal noção de melodrama paternal, bem como refletir sobre suas implicações na própria construção de imagens contemporâneas de masculinidade.

20. No original: "a trend to representing straight white masculinity as paternity" (REHLING, 2009, p. 11). 
21. É curioso pensar que a disparidade do valor sacrificial no melodrama paternal e no maternal, reservando a um aclamação e glórias e ao outro o anonimato e o esquecimento, não deixa de reproduzir, a sua maneira, noções opressivas de feminilidade e masculinidades destacadas anteriormente.

22. No original: "demonstrate how it is possible for men to respond to feminist demands 'in such a way as to make women the more marginal than ever" (REHLING, 2009, p. 18).

\section{Referências}

BALTAR, Mariana. Realidade Lacrimosa: o melodramático no documentário brasileiro contemporâneo. Niterói: EDUFF, 2019.

BALTAR, Mariana. Tessituras do excesso: notas iniciais sobre o conceito e suas implicações tomando por base um procedimento operacional padrão. Revista Significação, São Paulo, v. 39, n. 38, p. 124-146, 2012. DOI: https://doi. org/10.11606/issn.2316-7114.sig.2012.71141.

BROOKS, Peter. Reading for the Plot: Design and Intention in Narrative. Nova York: Knopf, 1984.

BROOKS, Peter. The Melodramatic Imagination Balzac, Henry James, melodrama and the mode of excess. Londres: Yale University Press, 1995.

CARTA de uma desconhecida. Direção: Max Ophuls. Universal Studios. DVD, 87 min, 1948.

DAY, Randal. D.; LAMB, Michael. E. Conceptualizing and measuring father involvement: Pathways, problems and progress. Mahwah: Lawrence Erlbaum Associates Publishers, 2004.

ELSAESSER, Thomas. Tales of Sound and Fury: Observations on the Family Melodrama. In: GRANT, Barry Keith (org.). Film Genre Reader III. Austin: University of Texas Press, 2003. p. 366-395.

GLEDHILL, Christine. The Melodramatic Field: An Investigation. In: GLEDHILL, Christine (ed.). Home Is Where the Heart Is: Studies in Melodrama and the Woman's Film. Londres: British Film Institute, 1987. p. 05-39.

KAPLAN, E. Ann. Mothering, feminism and representation. The maternal in melodrama and the woman's film 1910 - 1940. In: GLEDHILL, Christine (ed.). Home Is Where the Heart Is: Studies in Melodrama and the Woman's Film. Londres: British Film Institute, 1987. p. 113-137.

KRAMER vs Kramer. Direção: Robert Benton. DVD, Columbia Pictures/Stanley Jaffe Production 105 min, 1979.

LANGER, Susanne. The Comic Rhythm. In: CORRIGAN, R. (ed.). Comedy: Meaning and Form. Nova York: Harper and Row, 1981.

LAS Abandonadas. Direção: Emilio Fernandez. DVD. Films Mundiales, 103 min, 1945.

LAVANDIER, Yves. La Dramaturgia: los mecanismos de relato - cine, teatro, ópera, radio, televisión, cómic. Madri: EIUNSA, 2003.

MEDRADO, Benedito. Homens na Arena do Cuidado Infantil: Imagens Veiculadas pela Mídia. In: ARILHA, Margareth; RIDENTI, Sandra G. Unbehaum; MEDRADO, Benedito (orgs.). Homens e Masculinidades: outras palavras. São Paulo: Editora 34, 1998.

MITTELL, Jason. Complex TV - The Poetics of Contemporary Television Storytelling. Nova York/Londres: New York University Press, 2015. 
MITTELL, Jason. Complexidade narrativa na televisão americana contemporânea. Tradução de Andrea Limberto. Revista Matrizes, São Paulo, v. 5, n. 2, p. 29-52, jan./jun. 2012. DOI: https://doi.org/10.11606/issn.1982-8160.v5i2p29-52.

NEALE, Steve. Melodrama and tears. Screen, v. 27, n. 6, p. 6-23, nov./dez., 1986. DOI: https://doi.org/10.1093/screen/27.6.6.

O CAMPEÃO. Direção: Franco Zeffirelli. DVD. Hialeah Park Studios/MGM (MetroGoldwyn-Mayer), $121 \mathrm{~min}, 1979$.

PAIXÕES sem freios. Direção: Vincente Minnelli. MGM (Metro-Goldwyn-Mayer) DVD, 134 min, 1955.

REHLING, Nicola. Extra-Ordinary Men: White Heterosexual Masculinity and Contemporary Popular Cinema. Lanham: Lexington Books, 2009.

RICOUER, Paul. Tempo e Narrativa. Tradução de Constança Marcondes César. Campinas: Papirus, 1995. (Tomo I).

SOBCHACK, Vivian. Child/alien/father: patriarchal crisis and generic exchanges. In: PENLEY, Constance (ed.). Close Encounters: Film, Feminism, and Science Fiction. Minneapolis: University of Minneapolis Press, 1991.

STELLA Dallas. Direção: King Vidor. DVD, The Samuel Goldwyn Company/United Artists. 106 min. 1937.

STERNBERG, Meir. Expositional Modes and Temporal Ordering in Fiction. Baltimore: Johns Hopkins UP, 1978.

THIS is us (temporadas 1 a 4) [Série TV]. Criador: Dan Fogelman. Múltiplos diretores. Produtra NBC Netwoek, 2016. Canal de streaming Fox Premium.

TUDO o que o céu permite. Direção: Douglas Sirk. Universal. DVD, 89 min, 1955.

TRUFFAUT, François. Hitchcock/Truffaut: entrevistas. Tradução: Rosa Freire Aguiar. São Paulo, Companhia das Letras, 2004.

VIEIRA, Marcel. Dramaturgia seriada contemporânea: aspectos da escrita para a tevê. Lumina, Juiz de Fora, v. 8, n. 1, jun. 2014. DOI: https://doi.org/10.34019/19814070.2014.v8.21122.

VINCENT-BUFFAULT, Anne. História das Lágrimas. Tradução de Luiz Marques e Martha Gambini. Rio de Janeiro, Paz e Terra, 1988.

VIVIANI, Christian. Who is without sin? The maternal melodrama in American Film, 1930 - 39. In: GLEDHILL, Christine (ed.). Home Is Where the Heart Is: Studies in Melodrama and the Woman's Film. Londres: British Film Institute, 1987. p. 83-99.

WELZER-LANG, Daniel. A construção do masculino: dominação das mulheres e homofobia. Tradução de Miriam Pillar Grossi. Revisão de Helena Heloísa Fava Tornquist. Revista Estudos Feministas, Florianópolis, v. 9, n. 2, p. 460-482, 2001. DOI: https://doi.org/10.1590/S0104-026X2001000200008.

WILLIAMS, Linda. Film Bodies: gender, genre and excess. In: GRANT, Barry Keith (org.). Film Genre Reader III. Austin: University of Texas Press, 2003. p. 141-159.

WILLIAMS, Linda. Playing the Race Card: Melodramas of Black and White from Uncle Tom to O. J. Simpson. Princeton: Princeton University Press, 2001.

WILLIAMS, Linda. Something else besides a mother - Stella Dallas and the maternal melodrama. In: GLEDHILL, Christine (ed.). Home Is Where the Heart Is: Studies in Melodrama and the Woman's Film. Londres: British Film Institute, 1987. p. 299-325. 
XAVIER, Ismail. O olhar e a cena: melodrama, Hollywood, cinema novo, Nelson Rodrigues. São Paulo: Cosac \& Naify, 2003.

ZUBERBUEHLER, Kelsey. Role of Flashbacks in Relationship Depiction in this is Us. Communication Studies Undergraduate Publications, Presentations and Projects. 85. Portland, Oregon: University of Portland, 2018.

Recebido em: 19/06/2020

Aceito em: 27/08/2020 